\title{
On some Factors Limiting the Habitat of Arenicola marina.
}

By

D. M. Reid,

Dept. of Biology, Harrow School.

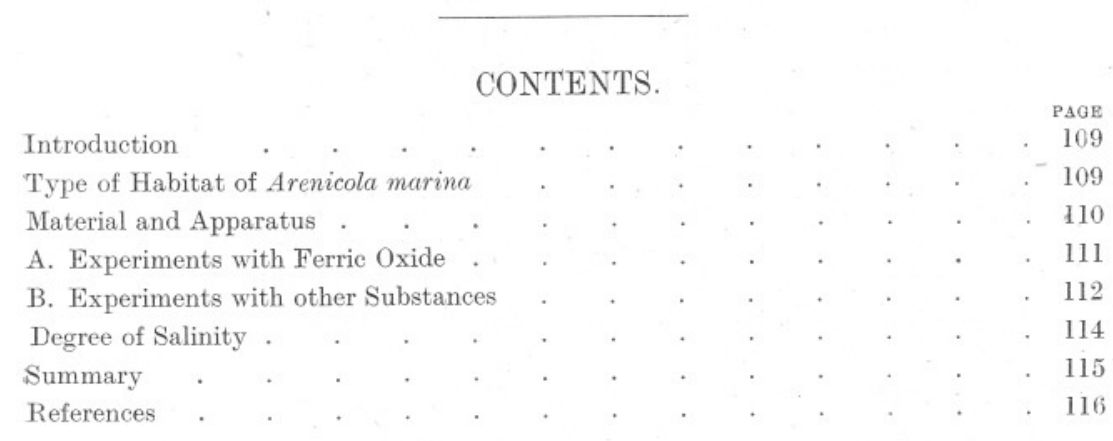

\section{INTRODUCTION.}

In connection with a certain problem in Palæontology (1) it became necessary to learn in what manner the marine burrowing worms of the past (but not the tubicolous worms) were likely to have behaved with regard to red oxide of iron in the amorphous state. Some of the sands (now rocks) in which those worms burrowed contained a large amount of iron oxide, others contained practically none at all. Owing, however, to certain differences and one particular common feature shown by the rocks in question, the following experiments were instituted in the hope that the habitat of the present-day worms might throw some light on the conditions of the past.

Type of Habitat of A. MARINA.

Curiously enough, despite all that has been written about $A$. marina no accurate details can be found dealing with either the nature of the ground material nor with the minimum density of the water tolerated by the organism.

With regard to the minimum density Benham (2) says, "A. marina lives equally well in water of very different density," and Ashworth (3) states that it occurs far up certain estuaries which, in times of flood at 
least, are of much less density than sea-water. He also quotes Bohn to the effect that the absence of $A$. marina from the northern parts of the Baltic may be due to the same cause.

The information dealing with the ground material is much more plentiful. The researches of Allen and Todd $(4,5)$ in the Salcombe and Exe estuaries would seem to show that $A$. marina in that locality is confined to a ground material consisting of mud and sand, mud and gravel, but very seldom, if ever, occurring in pure sand or pure mud. Ashworth (3) simply says that, " all species of Arenicola burrow in sand or gravel." Ferronnière (6) in his exhaustive survey of the Loire Estuary says that $A$. marina is found in sand containing an admixture of mud, but not in fresh deposits of mud where the water is flowing, although they were found in foetid mud. Here, I think it is necessary to draw some distinction between the different kinds of mud. Fœtid mud must contain some organic matter, while mud formed by silt may contain very little organic matter and can hardly ever become fœtid.

My own limited investigations have shown that Arenicola does not occur in very pure sand. Where such appears to be the case, digging almost invariably shows that the pure top layer overlies a bed of sand mixed with mud.

From the work of Davidson ( $\boldsymbol{y}$ ) it will be seen that the top layer of sand must be more or less purified since the worms pass vast quantities through their bodies annually and, in the process, remove the organic matter.

\section{Material and Apparatus.}

The material used in this work consisted of a number of specimens of Arenicola marina supplied by the Marine Biological Station at Plymouth, quantities of sea-sand and sea-water and the following substances in a very finely divided state which were not known to have lethal properties :--

Ferric oxide.

Calcium carbonate.

Magnesium carbonate.

Stourbridge clay.

Kaolin.

Kieselguhr.

The apparatus consisted of a number of wide-mouthed bottles of 150 c.c. capacity and several "gas jars," 10 inches high and 2 inches in internal diameter.

Aeration was effected by means of a filter-pump fixed to a water-supply tap and connected by rubber tubing via a 4 -way pipe to the various jars. 
The jars were fitted with rubber stoppers and two glass tubes. Aeration of the water was, therefore, caused by suction and not by blowing as is more usual. This method was found to be highly satisfactory and, by careful adjustment of the size of the pipes, no great head of water was necessary to ensure a constant supply of air.

\section{A. Experiments with Ferric Oxide.}

Three gas jars were used for this experiment. Each contained $300 \mathrm{gms}$. of fresh sea-sand and 250 c.c. of sea-water.

The control worm was placed in its jar (A1). It immediately burrowed into the sand where it remained throughout the course of the experiments.

To jar (A2) was added 2 gms. of ferric oxide. This was allowed to settle, and then, by means of a glass rod, was stirred into the sand to a depth of about one and a quarter inches. This layer represented about $1 \mathrm{gm}$. of the oxide to $50 \mathrm{gms}$. of sand. When this had stood for an hour and very little oxide remained in suspension a worm was introduced. It immediately showed every sign of discomfort, wriggling into knots and everting and introverting its pharynx.

It made no attempt to burrow other than to place its anterior extremity against the sand and remove it almost immediately. When its movements began to slacken in vigour the organism was removed from the jar and revived in pure sea-water.

Fifty grammes of fresh sand were then poured evenly over the top of the sand and oxide, the water was pipetted off and a fresh supply added, thus ensuring that there was practically no iron oxide in suspension nor in direct contact with the water.

The same worm was again introduced. At first it remained quite still, but soon it began to burrow. The burrow extended down vertically only as far as the surface of the layer of oxide when it tended to run parallel to it, but never pierced it.

Jar (A3). A specimen of Arenicola marina was placed in a jar containing sand with a layer of iron oxide overlaid with $\frac{3}{4}$ inch of pure sand. The worm immediately started to burrow. On reaching the oxide it withdrew from the sand. This burrowing down to the oxide and complete withdrawal on coming in contact with it occurred several times. Ultimately, however, the burrow was continued along the surface of the oxide.

After a time, since the worm showed no sign of piercing the oxide, it was removed and placed in a jar containing only pure sand and seawater. It was noticed that a small amount of the oxide had adhered to the anterior end of the worm. At first it made no attempt to burrow, but after lying quiescent for about three hours (after which time the 
oxide, although still there, was more in the nature of a layer of mucus containing iron oxide than a direct layer of the oxide on the worm), it burrowed completely.

Jar (A4). The conditions in this experiment were exactly similar to those in the previous experiment. Again the worm burrowed down to the surface of the oxide, but it did not withdraw from the burrow. After a certain amount of hesitation it continued the burrow parallel to the surface of the oxide. When no further effort was made to burrow vertically the worm was removed and placed in a jar of pure sand and sea-water. The anterior end of this worm had only a trace of oxide adhering to it. Burrowing commenced in just over an hour.

Jar (A5) was similar to (A1) in composition except that the sand contained $1 \mathrm{gm}$. of ferric oxide evenly distributed throughout. On top of this mixture a very thin layer of pure sand was spread. When a worm was introduced it almost immediately pierced the pure sand, but hesitated when it came into contact with the underlying mixture. However, after a few abortive attempts it ultimately burrowed right down until it was completely immersed. Its behaviour differed from that of the control in as much as while the control remained buried this specimen soon protruded its posterior end from the burrow and remained in that position until stimulated by tapping the jar or by shutting off and turning on the air supply suddenly. From these results it will be seen that Arenicola marina found the presence of ferric oxide repellent under two conditions only, viz. :-

1. When the water contained it in suspension.

2. When mixed with sand in a high proportion (1 gm. oxide to 50 gms. sand).

Since it appears to be more likely that Arenicola under natural conditions would come into contact with the ferric oxide in suspension in water, rather than the oxide-sand mixture, a further set of experiments were set going in order to find out the effect of the suspension on the worm.

To this end a suspension was made up of $0.5 \mathrm{gm}$. of the oxide in 100 c.c. sea-water. When a worm was introduced it immediately showed symptoms of acute discomfort in the usual way, i.e. by violent wriggling, etc. After six hours this worm ceased to show any movement and could not be revived.

\section{B. Experiments with other Substances.}

These results, of course, merely suggest that ferric oxide is abhorrent to Arenicola, so the following experiments were undertaken to find if the substance were lethal, and if so, in what quantity. The apparatus 
used was essentially the same as formerly, except that wide-mouthed bottles of 150 c.c. capacity were used instead of jars.

Three such bottles were fitted up as follows: water 140 c.c., with

$\begin{array}{lcl} & \text { Ferric oxide. } & \text { Worm, size. } \\ \text { B1 } & 0.00 \mathrm{gm} . & \text { Medium. } \\ \text { B2 } & 0.05 \mathrm{gm} . & \text { Large. } \\ \text { B3 } & 0.03 \mathrm{gm} . & \text { Small. }\end{array}$

Almost immediately after introducing the oxide to bottles B2 and B3 it had completely enveloped both worms in a thin layer, but with this difference, worm B2 had practically all the available oxide adhering to it while worm B3 had only a portion of the available oxide adhering to it, although it was as completely enveloped as B2. (This, of course, was owing to its smaller size.)

The oxide, it may here be explained, was caught and retained by the mucus secreted by the worm.

In the case of worm B2, after 20 hours, the movements of the organism caused the oxide-laden sheath of mucus to be formed into a band about $1 \mathrm{~cm}$. wide towards the anterior end, and from this time onwards the worm began to revive.

B3, however, was not so happily situated. No sooner did the mucous sheath begin to shorten than the parts so exposed collected a further coat of the oxide not previously collected. This coat it did not survive.

From this it can be concluded that ferric oxide in the amorphous state is not necessarily an active poison as far as Arenicola marina is concerned, but that it is lethal only when it can form with the mucus secreted by the organism a coat to shut off contact with the surrounding water for a sufficiently long period, and so inhibit respiration.

The difference between the case of A3 and B3 (when A3 lived in sand containing $0.3 \%$ of the oxide in sand while B3 was killed by $0.021 \%$ ) may be explained by the fact that by burrowing through the sand the layer of oxide is scraped off with the mucus used to support the walls of the burrow.

If, as has been said, ferric oxide is lethal only in virtue of its physical properties, other substances of similar physical properties ought to act in the same way towards Arenicola.

To this end the B group of tests were repeated in exactly the same manner with (1) Calcium carbonate, (2) Magnesium carbonate, (3) Stourbridge clay, (4) Kaolin and (5) Kieselguhr. The results were so near those got with ferric oxide that it would merely be repetition to give details of the individual results, although it was noted that the kaolin appeared to be more intensely irritating to the worm than any of the others. 
At the suggestion of Dr. Orton (to whom I am deeply indebted) these experiments were repeated in order that any alteration in hydrogen ion concentration might be checked.

The original sea-water was $\mathrm{pH} 7 \cdot 95$. The hydrogen ion concentration at the end of the experiment was found to have increased in the case of the control to $\mathrm{pH} 8 \cdot 05$. At the death of the worms it was $\mathrm{pH} 8 \cdot 15$ except in the case of the calcium carbonate where it reached the maximum of $\mathrm{pH} 8 \cdot 35$.

These results seem to prove, therefore, that it is the physical form and not the chemical composition of the substance which the organisms find intolerable.

\section{Degree of SALINIty.}

Although the foregoing results would seem to show that Arenicola marina is unlikely to be found living in places where a large amount of fine sediment is brought down in suspension, it was found desirable to secure some data as to the degree of salinity of the water which would be necessary for the life of the organisms in estuaries. In this connection the jars each contained $100 \mathrm{gms}$. fresh sand.

C1 was used as a control with pure sea-water. C2-C5 contained respectively diluted sea-water, $75 \%, 50 \%, 30 \%$, and $20 \%$.

After four days no difference could be detected between the condition of the worms in $\mathrm{C} 1, \mathrm{C} 2$.

C3 and C4, however, were very much less active and showed no inclination to burrow, although they moved about in a feeble manner.

C5 remained almost motionless except for very inconspicuous rhythmic contractions. The condition of the organisms (C3-C5) may best be described as of such extreme turgidity that they were quite unable to exercise any power of locomotion, so that as burrowing worms they had ceased to exist.

An attempt was then made to find to what extent Arenicola marina could be slowly acclimatised to reduced salinity. Sea-water of salinity $35 \cdot 2 \%$ was used as standard ( $\mathrm{pH} 7 \cdot 95)$.

Three 150 c.c. bottles were used.

$$
\begin{aligned}
& \text { C6 . . Control. } \\
& \mathrm{C} 7 \text {. } 50 \text { pts. sea-water to } 50 \text { pts. fresh. } \\
& \text { C8. Normal sea-water. }
\end{aligned}
$$

Ten c.c. distilled water was added every 24 hours at first, but owing to the condition of the worm less frequent additions were made towards the end. (On several occasions the bottles became too full and some of the mixture had to be poured off.)

C7 became rather turgid when placed in the mixture, but moved about 
slightly. On the addition of more fresh water it practically ceased to move and only its turgid state indicated the condition of life. On the fifth day, however, it died-becoming quite flaccid-and the salinity was found to be $3 \cdot 10 \%$ o $(\mathrm{pH} 7 \cdot 65)$.

C8 lived normally for the first four days after which, though never showing so much turgidity as $\mathrm{C} 7$, its movements slowed down and it died on the eighth day when the salinity of the water was $14.39 \%$ o ( $\mathrm{pH} 7 \cdot 85)$.

While these experiments were going on the control worm of the previous experiment in its bottle was still being aerated, and at the same time evaporation was going on so that the salinity was gradually increasing. It was not noticed that the worm as a whole became any thinner or less active, but the effect on the caudal end was most marked. The latter did not become generally attenuated, but became reduced in length and constricted at three places, more or less equidistant, so that the part appeared as a series of knots. At the death of this worm (after evaporation had been going on for 12 days) the salinity was found to be $37 \cdot 4 \%$ and the $\mathrm{pH} 8.05$.

From $\mathrm{C} 7$ and $\mathrm{C} 8$, taken in conjunction with the previous lot of experiments, it would appear that $A$. marina does not tend to adapt itself to any great change in salinity, its range probably lying between $35 \%$ o and $25 \%$ for, although it may actually live beyond those limits in the Laboratory, it could not do so under natural conditions.

Also, it should be noted that no sand was placed in the vessels with the worms during the latter experiments because of the fact that no guarantee could be given that the sand contained water of the same salinity as that above the sand.

\section{SUMMARY.}

In the foregoing work it was found that: Arenicola marina was repelled and could not burrow in sand containing $2.0 \%$ of ferric oxide in the amorphous state.

That $0.021 \%$ ferric oxide in suspension in sea-water was lethal owing to its forming with the mucus of the organism an envelope which prevented contact with the surrounding air-carrying water.

That calcium carbonate, magnesium carbonate, Stourbridge clay, kaolin, and kieselguhr had the same effect as the ferric oxide in suspension.

That although able to live for a short time in water of salinity $3 \cdot 10 \%$, Arenicola marina tended to become so turgid in water of $14.32 \%$ as to be unable to burrow. 


\section{REFERENCES.}

1. Macnair, P., and ReID, D. M. "On the mode of occurrence of Scolithus linearis in the N.W. Highlands." Geol. Mag., Vol. LXVI, No. 776, 1929.

2. Benham, W. B., Cambridge Natural History, Vol. II, 1909.

3. Ashworth, J. H. Catalogue of the Chætopoda in the British Museum. A. Polychæta. Pt. I, Arenicolidæ.

4. Allen, E. J., and Todd, R. A. Journal Mar. Biol. Assn., n.s., Vol. VI, 1900 , p. 151.

5. Allen, E. J., and Todd, R. A. Journal Mar. Biol. Assn., n.s., Vol. VI, 1902, p. 295.

6. Ferronnière, G. Bull. Soc. Sci. Nat. Ouest France, Tome II, 2e Ser., No. I, 1901.

7. Davidson. "Work done by Lobworms." Geol. Mag., 1891, p. 489. 